monly administer it in a gummy solution, fire decistammes (ten grains) of the salt diseolved in 100 grammes* of the fluid. One of its great adrantages is, that it can be easily dissolved in oil, and thus serve for frictions and embrocations over the spleen. For this purpose we have used the following liniment :-

60 grammes of olive oil.

1 gramme of valerianate of quinine.

In neuralgia we commonly employ pills of six centigrammes each, made up in the most simple manner.-Gazette Médicale de Paris.

- A gramme is equal to $\mathbf{1 5 . 4 3 4}$ grains troy:

\section{ROYAL COLLEGE OF SURGEONS.}

Gentlemen admitted Members on Priday, December 20th, 1844 :-G. J. Wycherley; J. Jolliffe; H. J. Aldham; G. E. Givins; G. Rigden ; J. T. Newberry; J. W. Littler; J. Maison; C. Townsend.

The Mr. Cotton mentioned in the list of new Fellows curritted by examination, is Charles Cotton, Esq., of Lynn Regis, (not of Lyme, as formerly stated,) surgeon to the West Norfolk and Lynn Hospital.

METEOROLOGICAL JOURNAL FOR O CT O B E R, 1844.

Kept at Sidmouth,

By W. H. Cullen, M.D., Surgeon.

Mean of External Thermometer at 9 A.M. 54.34

. . . . . . . . . P.M. 41.80

- . . . the Maxima, . . . 57.50

. . . . Minima, .. . . 45.05

Mean daily range. 11.70

Extreme highest on the 4th . . . 65.50

- lowest, on the 19th . . . . 36 . Extreme range. 29.50

Mean Dewpoint at 9 A:M. $\quad$ - . 50.71

. . . . . P.M. . . . . 47.10

Nean of Barometer at 9 A.M. . . . 24.700

. . . . . P.M. . . . . 29.055

Ditreme highest on the 27 th . . . . 30.250

- lowest on the 9th . . . . 28.950

Extreme range. 1.300

Number of days fine. . . . . . 15

- . - on which any rain fell . 16

Quantity of rain in inches . . . . . 1.74

PREVAILING WINDS.

\begin{tabular}{|c|c|c|c|c|c|c|c|c|c|}
\hline N. & N.E. & E. & S.E. & S. & S.W. & W. & N.W. \\
\hline 3 & 1 & 1 & 0 & 3 & 8 & 6 & 5 & 5 \\
\hline
\end{tabular}

\section{OBITUARY.}

December 5th, at Cork, Dr. Bullen, aged 78, for a long time a leading practitioner in the south of Ireland. His funeral was attended by the members of the medical and clerical professions, and a large number of the respectable inhabitants of the city.

December 7th, at Dublin, from the effects of a fall from his horse, Dr. Joseph Stephens, medical superintendent of the mining district of Beerhaven.

December 10th, at Portumna, of malignant typhus, Dr. John.Heron.

\section{BOOK RECEIVED.}

The Principles and Practice of Obstetric Medicine and Surgery, in reference to the Process of fyturition. By Francis H. Ramsbotham, M.D., Fellow of the Royal College of Physicians, Consulting Physician and Lecturer on Obstetric and Forensic Medicine at the London Hospital, \&c., \&c. Second Edition, enlarged. London : Churchill, 1844, 8vo., pp. 732, with numerous illustrations.

\section{ERRATUM.}

In Mr. Hancock's tenth lecture, p. 574, col. 2, line 4 from the end for "teres minor" read teres major.

\section{TO CORRESPONDENTS.}

Communications have beer received from Mr. Carter ; Mr. W. F. Clark; H.; Dr. Durrant ; Dr. R. H. Powell; A Genal Practitioner; East- Retford; Mr. H. R. Oswald ; : Black; Halifux; Mr. J. Cole.

With the view of consulting the convenience of those gentlemen who are now about to join the Association, we propase to commence the year with a new volume; the present number therefore concludes the volume for 1844, the title page and index to which will be given early in January.

It is requested that all letters and communications. be sent to Dr. Streeten, Foregate Street, Worcester. Parcels, and books for review, may be addressed to the Editor of the Provincial Medical and Surgical Journal, care of Mr. Churchill, Princes Street, Soho. 